\title{
Sam68 mediates leptin signaling and action in human granulosa cells: possible role in leptin resistance in PCOS
}

\author{
Teresa Vilariño-García1,* Antonio Pérez-Pérez ${ }^{1, *}$, Esther Santamaría-López ${ }^{2}$, Nicolás Prados² \\ Manuel Fernández-Sánchez ${ }^{2}$ and Víctor Sánchez-Margalet ${ }^{1}$ \\ 1Department of Medical Biochemistry, Molecular Biology and Immunology. Medical School, Virgen Macarena University Hospital, University of Seville, \\ Seville, Spain \\ ${ }^{2}$ Valencian Infertility Institute (IVI), Seville, Spain
}

Correspondence should be addressed to V Sánchez-Margalet: margalet@us.es

*(T Vilariño-García and A Pérez-Pérez contributed equally to this work)

\begin{abstract}
Introduction: Polycystic ovary syndrome (PCOS) is a complex metabolic disorder associated with ovulatory dysfunction, hyperandrogenism, obesity, and insulin resistance, that leads to subfertility. Sam68 is an RNA-binding protein with signaling functions that is ubiquitously expressed, including gonads. Sam68 is recruited to leptin signaling, mediating different leptin actions.

Objective: We aimed to investigate the role of Sam68 in leptin signaling, mediating the effect on aromatase expression in granulosa cells and the posible implication of Sam68 in the leptin resistance in PCOS.

Materials and methods: Granulosa cells were from healthy donors $(n=25)$ and women with PCOS $(n=25)$, within the age range of 20 to 40 years, from Valencian Infertility Institute (IVI), Seville, Spain. Sam68 expression was inhibited by siRNA method and overexpressed by expression vector. Expression level was analysed by qPCR and immunoblot. Statistical significance was assessed by ANOVA followed by different posthoc tests. A $P$ value of $<0.05$ was considered statistically significant.

Results: We have found that leptin stimulation increases phosphorylation and expression level of Sam68 and aromatase in granulosa cells from normal donors. Downregulation of Sam68 expression resulted in a lower activation of MAPK and PI3K pathways in response to leptin, whereas overexpression of Sam68 increased leptin stimulation of signaling, enhancing aromatase expression. Granulosa cells from women with PCOS presented lower expression of Sam68 and were resistant to the leptin effect on aromatase expression.

Conclusions: These results suggest the participation of Sam68 in leptin receptor signaling, mediating the leptin effect on aromatase expression in granulosa cells, and point to a new target in leptin resistance in PCOS.
\end{abstract}

Key Words
- Sam68
- leptin
- polycystic ovary syndrome
(PCOS)
- aromatase
- signalling pathways

Endocrine Connections (2020) 9, 479-488

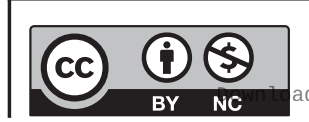

This work is licensed under a Creative Commons Attribution-NonCommercial 4.0 International License. ded from Bioscientifica.com at 04/26/2023 08:29:18AM 


\section{Introduction}

Sam68, the Src-associated substrate during mitosis of $68 \mathrm{kDa}$, also known as KHDRBS1, is a member of the family of RNA binding proteins $(1,2,3)$. This protein participates as a scaffold protein recruited in various signal transduction pathways $(4,5,6,7)$, linking signaling pathways and RNA metabolism regulation (3). Both Sam68 splicing activity as RNA binding ability and other functions are mainly regulated by phosphorylation $(8,9)$. In this sense, the tyrosine phosphorylation of Sam68 has been previously implicated in cell proliferation, growth as well as in differentiation processes through different mechanisms. In fact, Sam68 phosphorylation has been reported to be stimulated by mitogenic and trophic hormones such as leptin (via PI3K and MAPK pathways activation $(10,11)$ ) (Fig. 1), where it has been linked to cellular growth and differentiation processes. Moreover, numerous physiological roles for this RNA binding protein have been reported using Sam68-deficient mice. For example, Sam68 protein is highly expressed in the gonads, where its ablation causes male infertility, due to defects in spermatogenesis $(10,12)$. Besides, Sam68 $8^{-/-}$ females are severely subfertile, and they show a delay in the age of first pregnancy, increased breeding time for successful pregnancy and yielded smaller litters (13). Thus, a function for Sam68 in reproduction and fertility has been suggested $(13,14)$, and modulation of its activity and/or expression levels probably could mediate various pathological situations.
Polycystic ovary syndrome (PCOS) is a common endocrine disorder that affects $5-10 \%$ of women at reproductive age (15). It has unknown origin and various clinical presentations during the life span. PCOS is characterized by the presence of ovulatory dysfunction, clinical and/or biochemical hyperandrogenism and polycystic ovarian morphology (16). Women with PCOS are more likely to require in vitro fertilization (17).

A pivotal role in the pathophysiology of this syndrome is played by visceral adiposity $(18,19)$, and therefore, current research is increasingly focusing on the discovery of novel biomarkers to further elucidate the complex pathophysiology of PCOS. In this sense, alterations of Sam68 metabolic pathways would contribute to reduce the oocyte viability, leading to subfertility or infertility observed in PCOS, which is why we aim to study the role of Sam68 in women with PCOS. More specifically, according to the previously described participation of Sam68 in leptin signaling (6), we aim to investigate the role of this protein in the signal transduction pathways that are activated by leptin in granulosa cells from healthy controls.

Leptin resistance is a common finding in obesity, where it has been shown to cause ovulatory dysfunction and infertility (frequently associated with PCOS) (20). Hyperleptinemia may inhibit the development of the mature oocyte directly and affect ovarian and adrenal steroidogenesis (21).

On the other hand, a number of in vitro studies have reported that leptin may stimulate estrogen expression by increasing the expression of the intracellular

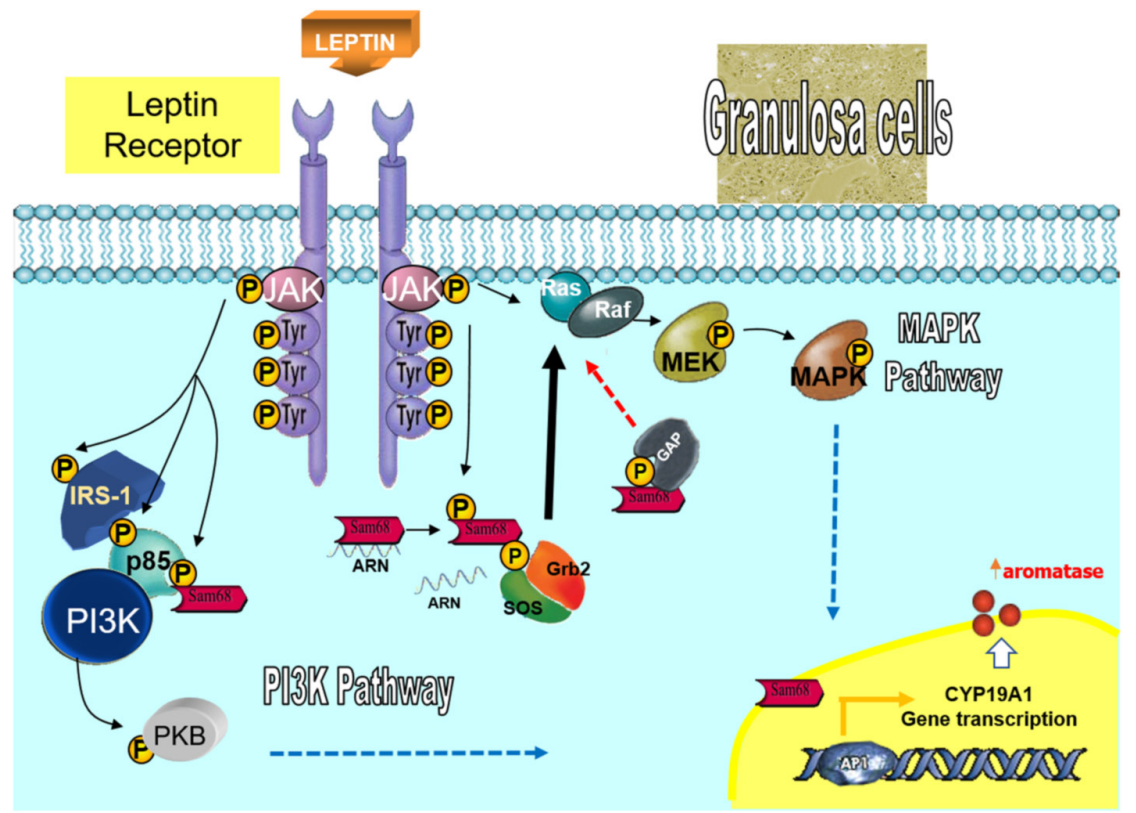

Figure 1

Mechanisms of leptin action in granulosa cells. The cartoon shows the signaling pathways that mediate the leptin effects on granulosa cells. Sam68 contains a domain for the RNA binding activity and it may interact with both RNA targets, as well as other proteins containing Src homology 3 (SH3) and $\mathrm{SH} 2$ domains through proline-rich sequences and tyrosine-phosphorylated residues, respectively. Sam68 is a scaffold protein recruited in various signal transduction pathways linking signaling pathways (PI3K and MAPK pathway) and RNA metabolism regulation. Sam68 functions are mainly regulated by phosphorylation. This tyrosine phosphorylation of Sam68 has been implicated in cell proliferation, growth as well as in differentiation processes through different mechanisms. Finally, Sam68 has been related to leptin-dependent PI3K and MAPK pathways activation, where it has been shown to be associated to Grb2, GAP and PI3K regulatory subunit in a different cellular system.

https://ec.bioscientifica.com https://doi.org/10.1530/EC-20-0062 (c) 2020 The authors Published by Bioscientifica Ltd

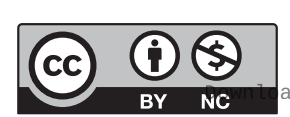

This work is licensed under a Creative Commons Attribution-NonCommercial 4.0 International License. ded from Bioscientifica.com at 04/26/2023 08:29:18AM 
aromatase enzyme, which catalyzes the rate-limiting step in the conversion of C19 androgens (androstenedione and testosterone) to C18 estrogenic steroids (estrone and estradiol). Thus, conflicting results of high leptin levels correlating with decreased aromatase expression $(22,23)$ may be due to leptin resistance. In this sense, diminished signaling has been found in GCs from PCOS women even though leptin levels are increased in follicular fluid (24). Low aromatase activity has also been demonstrated in women with PCOS. Therefore, we have hypothesized that the lower expression of aromatase in GC from PCOS could be caused by leptin resistance and that Sam 68 could be an underlying factor and thus a novel target in PCOS.

In the present study, we aimed to investigate the role of Sam68 in leptin signaling pathways in GCs, mediating the expression of aromatase, as well as to analyze the relationship between Sam68 and aromatase expression in GCs from patients with PCOS, in comparison with healthy controls.

\section{Materials and methods}

The study was approved by the Institutional Ethics Committee for human research of the Virgen Macarena University Hospital and conducted according to the principles expressed in the Declaration of Helsinki. All included adult participants provided written informed consent before the collection of samples

\section{Subjects}

We included women with PCOS from Valencian Infertility Institute (IVI), Seville, Spain. All women were evaluated through a standardized screening protocol which has been previously described in detail elsewhere (25). PCOS was diagnosed according to the Rotterdam criteria in the presence of two or more of the following criteria: oligoand/or anovulation, clinical and/or biochemical signs of hyperandrogenism and polycystic ovarian morphology as assessed by transvaginal ultrasound (26). We also included healthy donor women without PCOS with regular menstrual cycles (21-35 days), as well as women undergoing IVF/ICSI treatment in the IVI clinic. Women were within the age range of 20 to 40 years, and obese subjects, patients with endometriosis and poor ovarian response were excluded from the study. No differences were found in the mean age $(33.3 \pm 5.2$ PCOS subjects, and $25.2 \pm 4.8$ control subjects) or BMI $(25.4 \pm 0.4$ PCOS, and $24 \pm 1.8$ control subjects).

\section{Human granulosa cell isolation and culture}

Luteinized granulosa cells (GCs) from follicular aspirates were isolated using the protocol described in the literature by Ferrero et al. (27). GCs from healthy donor were seeded in six-well dishes and incubated overnight $\left(37^{\circ} \mathrm{C}, 5 \% \mathrm{CO} 2\right)$ to enable removal of non-adherent cells. Subsequently, GCs from each patient were washed and cultured for $24 \mathrm{~h}$ in Mc Coy's medium (BioWhittaker®) supplemented with $10 \%$ fetal calf serum (FCS), $100 \mathrm{U} / \mathrm{mL}$ penicillin and $100 \mathrm{~g} / \mathrm{mL}$ streptomycin at $37^{\circ} \mathrm{C}$ in $5 \% \mathrm{CO} 2$. Next, GCs were treated with or without leptin $(10 \mathrm{nM})$ for $10 \mathrm{~min}$ or $16 \mathrm{~h}$ in medium without FCS. The recombinant human leptin was provided by Sigma (Sigma Chemical); $10 \mathrm{nM}$ dose of leptin was used for both the experiments of inhibition and sobrexpression of sam 68 corresponding to our previously described results of optimal dose response (28).

The cell lisates were washed with cold PBS and solubilized for $30 \mathrm{~min}$ at $4^{\circ} \mathrm{C}$ in lysis buffer containing $20 \mathrm{mM}$ Tris, $\mathrm{pH} \mathrm{8}, 1 \%$ Nonidet P-40, $137 \mathrm{mM} \mathrm{NaCl}$, $1 \mathrm{mM} \mathrm{MgCl} 2,1 \mathrm{mM} \mathrm{CaCl} 2,10 \%$ glycerol, $1 \mathrm{mM}$ phenylmethylsulfonyl fluoride and $0.4 \mathrm{mM}$ sodium orthovanadate. Total protein levels were determined by the bicinchoninic acid method (29) using BSA as standard.

\section{Immunoprecipitation}

Soluble cellular lysates ( $0.5 \mathrm{mg}$ of protein) from GCs were precleared with $50 \mu \mathrm{L}$ of protein A-sepharose (Pharmacia, Uppsala, Sweden) for $2 \mathrm{~h}$ at $4^{\circ} \mathrm{C}$ by end-over-end rotation.

The precleared cellular lysates were incubated with anti-Sam68 (C-20) 1:1000 from Santa Cruz Biotechnology for $3 \mathrm{~h}$ at $4^{\circ} \mathrm{C}$ (30). Next, $50 \mu \mathrm{L}$ of protein A-sepharose was added to immune complexes and incubation continued for $2 \mathrm{~h}$. The immunoprecipitates were washed three times with lysis buffer. We added $30 \mu \mathrm{L}$ of SDS-stop buffer containing $100 \mathrm{mM}$ dithiothreitol (DTT) to the immunoprecipitates, followed by boiling for $5 \mathrm{~min}$. Soluble supernatants were then resolved by Western blotting by using $7-10 \%$ SDS-PAGE and electrophoretically transferred onto nitrocellulose membranes (11).

\section{Western blotting analysis}

Cell lysates and immunoprecipitates were denatured with $30 \mu \mathrm{L}$ of SDS-stop buffer containing $100 \mathrm{mM}$ of DTT followed by boiling for $5 \mathrm{~min}$. The soluble supernatants were then resolved by $7-10 \%$ SDS-PAGE and electrophoretically transferred onto nitrocellulose

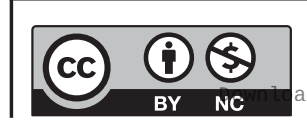

This work is licensed under a Creative Commons Attribution-NonCommercial 4.0 International License. ded from Bioscientifica.com at 04/26/2023 08:29:18AM via free access 
membranes. The membranes were blocked with buffered saline $-0.05 \%$ Tween 20 (PBST) containing 3\% albumin for $1 \mathrm{~h}$ at $23^{\circ} \mathrm{C}$. The blots were then incubated with primary antibody for $1 \mathrm{~h}$. Anti-Sam68 (C-20) 1:1000 was from Santa Cruz Biotechnology, anti-GAPDH 1:1000 and anti phosphotyrosine (4G10) 1:1000 were from Millipore, anti-phospho-ERK1/2 (pT202-Y204/ pT185-Y187) 1:1500, anti-phospho-AKT (pS473) 1:3000, and anti-phosphoIRS-2 1:2000 were from Cell Signalling Technology.

After the incubation with primary antibody, the membranes were washed in PBST and further incubated with the corresponding secondary antibodies using horse radish peroxidase-linked anti-rabbit/anti-mouse 1:10,000 immunoglobulin (GE Healthcare). Bound horseradish peroxidase was visualized by a highly sensitive chemiluminescence system (SuperSignal from Pierce).

\section{Transfection experiments}

GCs from healthy donors were plated onto six-well dishes containing $2 \mathrm{~mL}$ of Mc Coy's medium plus $10 \%$ FCS and incubated overnight $\left(37^{\circ} \mathrm{C}, 5 \% \mathrm{CO}_{2}\right)$ to enable removal of non-adherent cells. Medium was replaced, and transfection of cells was performed. For experiments involving gene silencing, cells were transfected with $2 \mu \mathrm{g}$ of siRNA oligonucleotides of Sam68 (Integrated DNA Technology) using LipofectAMINE (Life Technologies) transfection reagent according to the manufacturer's instructions.

Duplex sequences: forward, 5'-CGCAGAACA AAGUUACGAAGGCUAC-3'; reverse, 5'-GUAGCC UUCGUAACUUUGUUCUGCGUA-3'. Typically, 40 pmol of the Sam68 siRNA duplexes were transfected using $5 \mu \mathrm{L}$ of LipofectAMINE (Life Technologies). For experiments involving overexpression of Sam68, between 1 and $3 \mu \mathrm{g}$ of DNA was transfected into GCs. The pcDNA3 vector was used to equalize the amount of DNA in each transfection.

Following transfection, the medium was replaced with serum-free medium for another $24 \mathrm{~h}$ and the cells were stimulated with or without $10 \mathrm{nM}$ leptin for $10 \mathrm{~min}$. Transfection analyses were performed by duplicate in each of at least three independent experiments.

\section{RNA extraction and quantitative real-time-PCR (qRT-PCR) assay}

Relative abundance of aromatase and Sam68 mRNA was determined by qRT-PCR. After treatment with leptin, total RNA from GCs cultures was extracted using TRISURE reagent (Bioline Co) according to the manufacturer's instructions. Total RNA from both healthy donors and PCOS women was extracted. Concentration of the isolated RNA were estimated at 260 and $280 \mathrm{~nm}$ with purity in $\mathrm{A}_{260} / \mathrm{A}_{280}$ ratio around 2.0. For cDNA synthesis, $5 \mu \mathrm{g}$ of total RNA was reverse transcribed at $55^{\circ} \mathrm{C}$ for $1 \mathrm{~h}$ using the Transcriptor first Strand cDNA synthesis Kit (Roche). qRT-PCR was performed using the following primers based on the sequences of the National Center for Biotechnology Information GenBank database:

Sam68 (GeneBank accession: NM_006559.3): forward, 5'-TTTGTGGGGAAGAT TCTTGG-3'; reverse, 5' GGGGGTCCAAAGACTTCAAT-3'. cyclophilin (GeneBank accession: NM_000942): forward, 5' CTTCCCCGATACTTCA-3'; reverse, 5'-TCTTGGTGCTACCTC-3'3'. Aromatase (GeneBank accession: M18856): forward, 5' CCCTTCTGCGTCGTGTCAT-3'; reverse, 5' GATTTTAACCACGATAGCACTTTCG -3'. RPS-7 (GeneBank accession: NC_000002.12): forward, 5' ACCAAGAACTTTTTGCCCCT-3'; reverse, 5' ATGTCCCCCGAGTAATTTCC-3'.

Quantitative RT-PCR Master Mix Reagent kit was obtained from Roche (Fast Start Universal SYBR Green), and PCRs were performed on a Chromo 4 DNA Engine (Bio-Rad). Reaction contained $10 \mu \mathrm{M}$ of forward and reverse primer, $3 \mu \mathrm{L}$ of cDNA and the final reaction volume was $20 \mu \mathrm{L}$. The reaction was initiated by preheating at $50^{\circ} \mathrm{C}$ for $2 \mathrm{~min}$, followed by heating at $95^{\circ} \mathrm{C}$ for $10 \mathrm{~min}$. Subsequently, 41 amplification cycles were carried out as follows: denaturation $15 \mathrm{~s}$ at $95^{\circ} \mathrm{C}$ and $1 \mathrm{~min}$ annealing and extension at $58^{\circ} \mathrm{C}$. The threshold cycle (CT) from each well was determined by the Opticon Monitor 3 Program. Relative quantification was calculated using the $2^{-\Delta \Delta c t}$ method. For the treated samples, evaluation of $2^{-\Delta \Delta c t}$ indicates the fold change in gene expression, normalized to a housekeeping gene (cyclophilin or RPS-7) and relative to the untreated control.

\section{Data analysis}

Experiments were repeated separately at least three times to assure reproducible results. Results are expressed as means \pm S.D. in arbitrary units. Arbitrary units were calculated as normalized band intensity in Western blot analysis. Statistical analysis was performed using the Graph Pad Prism computer program (GraphPad

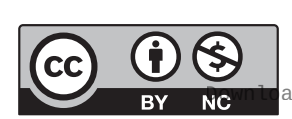

This work is licensed under a Creative Commons Attribution-NonCommercial 4.0 International License. ded from Bioscientifica.com at 04/26/2023 08:29:18AM via free access 
Software). Statistical significance was assessed by ANOVA followed by different post hoc tests, as indicated in each figure. A $P$ value of $<0.05$ was considered statistically significant.

\section{Results}

\section{Leptin increased Sam68 phosphorylation and mRNA expression in granulosa cells from healthy donors}

We have previously demonstrated the Tyr-phosphorylation of Sam68 in response leptin in different cell systems (11, $28,30,31,32$ ). Now, to assess whether Sam68 is involved in leptin's action on human GCs from healthy donors, we incubated GCs for $10 \mathrm{~min}$ in medium with or without different leptin concentrations (0.1-10nM) (Fig. 2). Leptin (Fig. 2A) increased the Sam68 phosphorylation in a dose-dependent manner, in GCs, as determined by Western blot analysis. This effect was dose dependent, and the maximal effect was achieved at $10 \mathrm{nM}$ leptin. The amount of total protein in every sample was controlled using anti-Sam68 antibodies.
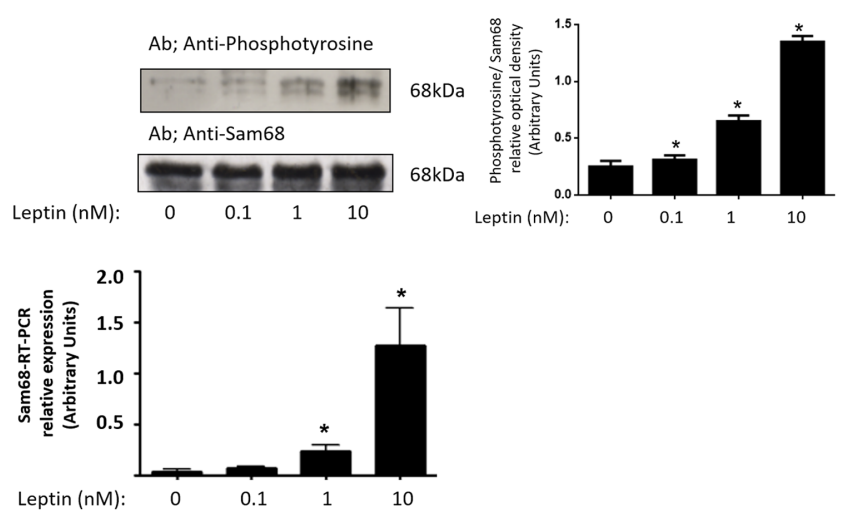

\section{Figure 2}

Leptin increases Sam68 phosphorylation in human GCs from healthy donors. (A) GCs were incubated in the absence or presence of leptin (0.1-10 nM) for $10 \mathrm{~min}$, lysed and the soluble clarified cell lysates were subjected to immunoprecipitation with anti-Sam68 antibodies. Immunoprecipitates were resolved by SDS-PAGE and Western blot with anti-phosphotyrosine antibodies. The lysates were analyzed by immunoblot using the anti-Sam68 antibodies to control the amount of protein in every lane. A representative experiment run in duplicates from three different donors is shown. Densitograms with S.D. are shown. $* P<0.05$ vs control. (B) Total RNA was extracted as described in Materials and Methods and Sam68 mRNA was quantified with qRT-PCR in independent experiments. Cyclophilin was used as internal standard. Results shown are expressed as means \pm s.D. from three independent experiments, run in triplicates, $* P<0.05$ vs control. Statistical analyses were performed by ANOVA. Asterisks indicate significant differences from the control according to Bonferroni's multiple comparison post hoc test.
In order to further study the effects of leptin on Sam68 expression, qRT-PCR analysis was carried out using cyclophilin as an internal control. GCs were independently incubated in the absence of serum with and without leptin $(0.1-10 \mathrm{nM})$ for $16 \mathrm{~h}$. As shown in Fig. 2B, expression level of Sam68 gene was increased in response to leptin, dose-dependently, and maximal effect was achieved at $10 \mathrm{nM}$ leptin.

\section{Sam68 down-regulation prevents leptin activation of signaling pathways in granulosa cells from healthy donors}

Leptin receptor is known to activate phosphatidylinositol-3 kinase (PI3K) and mitogen-activated protein kinase (MAPK). To test the effects of Sam68 down-regulation on leptin signaling, human GCs from healthy donors were used and immunoblotting was employed to analyze the phosphorylation of kinases.

Cells were grown to $60-70 \%$ confluence in six-well dishes and were first transfected using Sam68 siRNA or NC1 negative control siRNA duplexes and incubated in the absence or presence of leptin for $10 \mathrm{~min}$ as previously indicated in Material and Methods. Both anti-Sam68 and anti-GAPDH antibodies were used as control of Sam68 down-regulation and loading control, respectively. This approach achieved a decrease in Sam68 expression ranging between 60 and $70 \%$ of the control value (data not shown).

We measured the activation of PI3K pathways by employing antibodies that specifically recognize the phosphorylated forms of the central kinase PKB. Moreover, we also measured the activation of MAPK pathways by employing antibodies that specifically recognize the phosphorylated forms of ERK1/2. As shown in Fig. 3, leptin-mediated PKB and ERK1/2 phosphorylation was significantly reduced in GCs where Sam68 was downregulated. This effect was almost completely abolished by decreasing the expression of Sam68, suggesting the role of Sam68 in the leptin signaling pathways in GCs.

Finally, to connect Sam68 expression with the mechanistic effect that exerts over the main pathways PI3K and MAPK under leptin stimulation, we next focus on the effect of siRNA Sam68 down-regulation on the phosphorylated forms of insulin receptor substrate-1 (IRS-1) in human GCs. As it was demonstrated using immunoblotting analysis with anti-phospho-IRS-1 antibodies, down-regulation of Sam68 in GCs significantly decreased the phosphorylation of IRS-1 in response to leptin (Fig. 3).

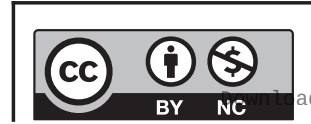



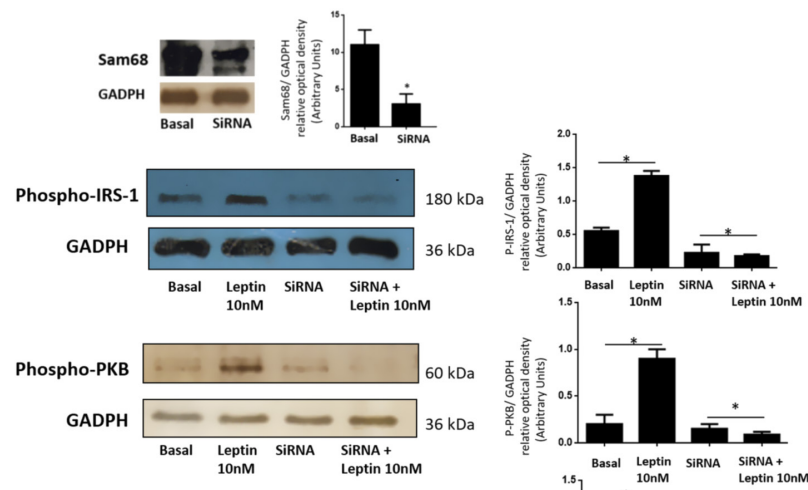

Phospho-ERK1/2
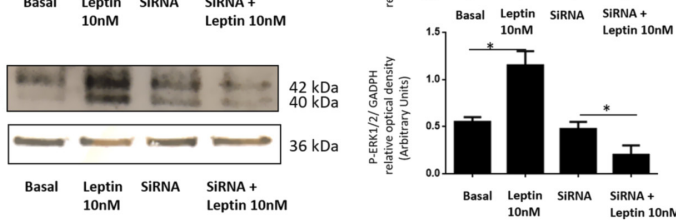

Figure 3

Sam68 siRNA prevents the leptin-dependent activation of PI3K and MAPK pathways in human GCs from healthy donors. GCs were transfected with Sam68 siRNA or NC1-scrambled negative control siRNA (basal) duplexes as described in Materials and Methods and incubated in the absence or presence of $10 \mathrm{nM}$ leptin for $10 \mathrm{~min}$. GCs lysates were separated by SDS-PAGE and Western blot analysis was performed by using anti-P-IRS-1, anti-P-PKB and anti-P-ERK1/2 antibodies to study leptin activation of the PI3K and MAPK signaling pathway. Sample protein loading was controlled by using anti-GAPDH antibodies. We show the control of the Sam68 expression inhibition as well as the corresponding densitometric analysis of three independent experiments as means \pm S.D. Statistical analyses were performed by ANOVA. Asterisks indicate significant differences from the controls un-treated and 'ns' no statistically significant difference according to Bonferroni's multiple comparison post hoc test.

\section{Sam68 overexpression increases leptin activation of signaling pathways in human GCs from healthy donors}

To further study the effect of Sam68 in leptin signaling pathways, we investigated the up-regulation of Sam68 by transfecting GCs from healthy donors with a pcDNA3 expressing Sam68 plasmid and pcDNA3 vector (empty vector) as control. Following transfection during $24 \mathrm{~h}$, the medium was replaced with serum-free medium for another $24 \mathrm{~h}$. Next, GCs were incubated in the absence or presence of $10 \mathrm{nM}$ leptin for $10 \mathrm{~min}$. As shown in Fig. 4, up-regulation of Sam68 increased the leptindependent activation of PI3K and MAPK pathways in GCs. More specifically, up-regulation of Sam68 increased the phosphorylation of IRS-1, PKB and ERK1/2. Maximal effect was obtained at $10 \mathrm{nM}$ leptin, suggesting again the role of Sam68 in the leptin signaling pathways in GCs.

\section{Effect of leptin on aromatase gene expression}

Although leptin was found to significantly increase aromatase gene expression and protein level $(33,34,35)$,

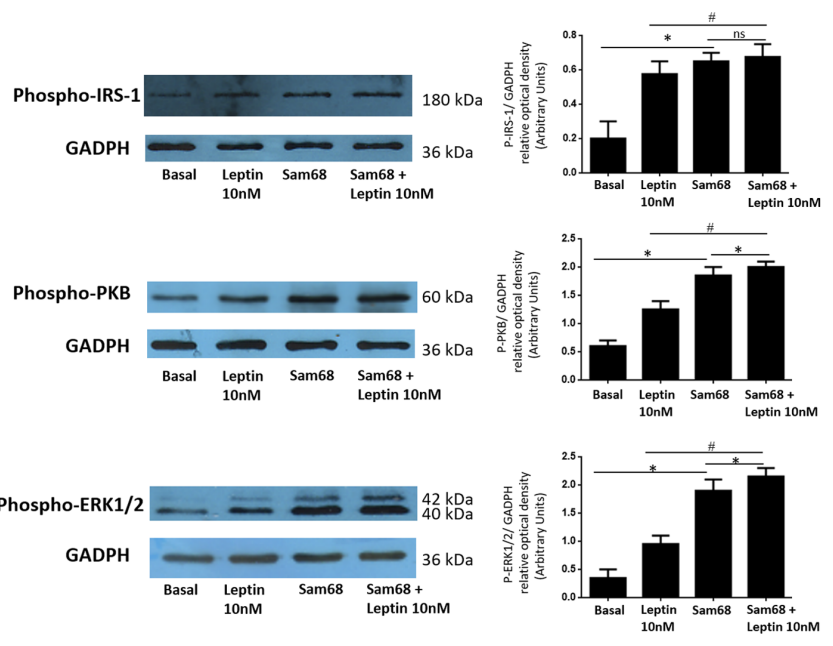

Figure 4

Sam68 overexpression increases the leptin-dependent activation of PI3K and MAPK pathways in human GCs from healthy donors. GCs were transfected with Sam68 plasmid and pcDNA3 (empty vector) as control (basal) as described in Materials and Methods, and incubated in absence or presence of leptin $10 \mathrm{nM}$ for $10 \mathrm{~min}$. GCs lysates were separated by SDS-PAGE and Western blot analysis was performed by using anti-P-IRS-1, anti-P-PKB and anti-P-ERK1/2 antibodies to study leptin activation of the PI3K and MAPK signaling pathway. Sample protein loading was controlled by using anti-GAPDH antibodies. We show the corresponding densitometric analysis of three independent experiments as means \pm S.D. Statistical analyses were performed by ANOVA. Asterisks indicate significant differences from the control and Sam68 plasmid without leptin. \# indicate significant differences from leptin $10 \mathrm{nM}$ and 'ns' no statistically significant difference according to Bonferroni's multiple comparison post hoc test.

its effect on aromatase in GCs from PCOS women is contradictory and unknown. Therefore, both GCs from healthy donors and PCOS women were grown for $24 \mathrm{~h}$ and treated with $10 \mathrm{nM}$ leptin for $24 \mathrm{~h}$. qRT-PCR analysis was carried out as previously indicated in Material and Methods, using RPS-7 as an internal control for reaction efficiency. The results showed that leptin stimulated significantly the expression of aromatase mRNA in GCs from healthy donors (Fig. 5A), possibly via activation of the canonical signal transduction pathways, MAPK and PI3K, as previously shown in other cellular systems (36). However, no significant changes in aromatase mRNA was detected after of 24-h leptin treatment in GCs from PCOS women (Fig. 5B), suggesting that some factors aberrantly expressed in PCOS could be inhibiting the leptin signal transduction pathways.

\section{Decreased Sam68 and and aromatase expression in human GCs from PCOS women compared to GCs from healthy donors}

Since Sam 68 protein is highly expressed in the gonads, we aimed also to compare the expression of Sam68 in GCs

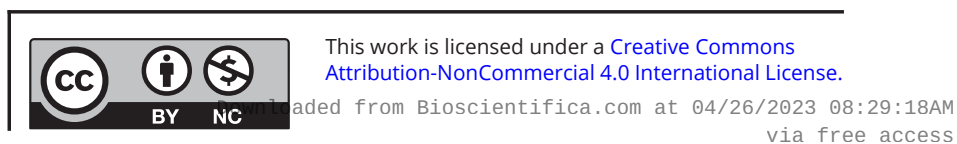



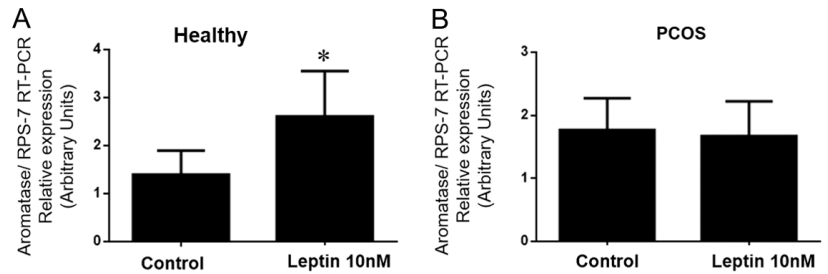

C
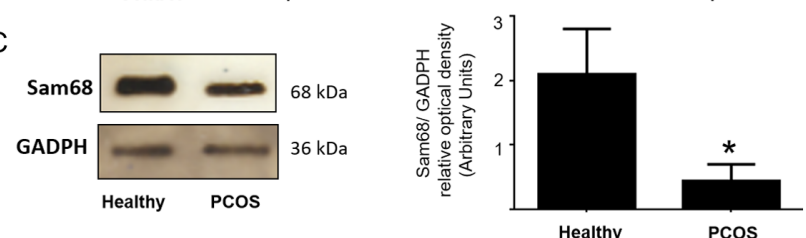

D
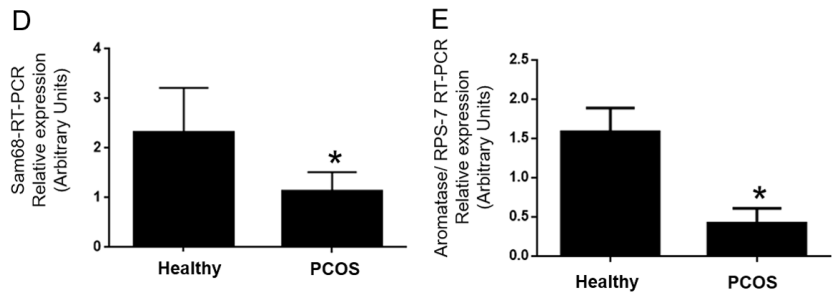

Figure 5

Effect of leptin on aromatase mRNA expression and diminished expression of Sam68 and aromatase in GCs from PCOS women. GCs samples were obtained from 25 healthy donors and 25 PCOS women. GCs were cultured in a medium containing $0 \%$ FCS for $24 \mathrm{~h}$. (A) GCs from healthy donors were treated with or without (control) $10 \mathrm{nM}$ leptin for $24 \mathrm{~h}$. (B) GCs from PCOS women were treated with or without (control) $10 \mathrm{nM}$ leptin for $24 \mathrm{~h}$. Aromatase gene expression was analyzed by qRT-PCR, normalized against RPS-7 and compared to the control group. (C) Representative Western blot analysis of Sam68 protein level in GCs from healthy donors and PCOS women. GCs lysates were denatured and resolved by SDS-PAGE with anti-Sam68 antibodies. Loading controls were performed in the same membranes with anti-GAPDH. We show the corresponding densitometric analysis of three independent experiments as means \pm S.D. Statistical analyses were performed by ANOVA. (D) Relative mRNA level of Sam68 in GCs from healthy donors and PCOS women. Sam68 mRNA was quantified with qRT-PCR. Cyclophylin was used as internal standard. Paired $t$-test was performed to examine the difference in mRNA level of Sam68 and statistical significance was considered when $P$ value was $<0.05$. (E) Relative mRNA level of aromatase in GCs from healthy donors and PCOS women, quantified by qRT-PCR. RNA was extracted as described in Materials and Methods. RPS-7 was used as internal standard. Paired $t$-test was performed to examine the difference in mRNA level of aromatase, and statistical significance was considered when $P$ value was $<0.05$. Asterisks indicate significant differences from the control according to Mann-Whitney $U$ test.

from patients diagnosed with PCOS vs those obtained from healthy donors, used as controls. We evaluated mRNA expression by means of qRT-PCR, using cyclophilin as an internal control for reaction efficiency. Moreover, immunoblotting analysis of Sam68 was performed as previously described in Materials and metods. As show in Fig 5C and D, Sam68 expression was lower in GCs from PCOS women than in GCs for healthy donors, suggesting a role played by Sam68 in these cells, which might allow this protein to affect different biological processes, such as, the aromatization step promoted by the aromatase enzyme. That is why we aimed also to compare the expression of aromatase in GCs from patients diagnosed with PCOS vs those obtained from healthy donors, used as controls. As show in Fig. 5E, aromatase expression was lower in GCs from PCOS women than in GCs for healthy donors, suggesting a role played by Sam68 in these cells.

\section{Effect of leptin on aromatase mRNA expression in overexpressed-Sam68 GCs from healthy donors}

Since Sam68 was observed to be downregulated in GCs from PCOS women and Sam68 modulates the leptin signaling pathways in GCs, as previously demonstrated, in order to further study the mechanical effect of leptin on aromatase expression, GCs from healthy donors were transfected with Sam68 plasmid and pcDNA3 as control. GCs were treated with or without (control) $10 \mathrm{nM}$ leptin for 48 h. As shown in Fig. 6, transfection with Sam68 plasmid significantly increased the expression levels of aromatase in GCs. Moreover, this effect of the upregulation of Sam68 on the expression of aromatase were more significantly increased when GCs were stimulated with $10 \mathrm{nM}$ leptin for $48 \mathrm{~h}$, suggesting a function of Sam68 in the aromatization step stimulated by leptin in GCs and, therefore, a possible role of Sam68 in the complex pathophysiology of PCOS.

\section{Discussion}

Reproductive dysfunction and infertility are common manifestations in PCOS (37). Understanding PCOS

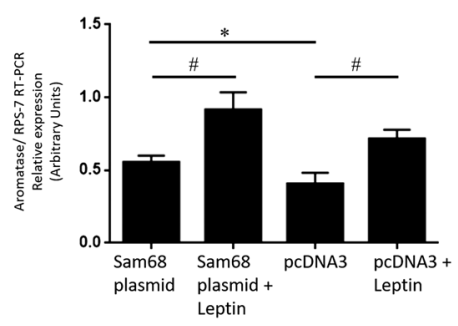

\section{Figure 6}

Effect of leptin on aromatase mRNA expression in control and Sam68overexpressed GCs from healthy donors. GCs were transfected with Sam68 plasmid and pcDNA3 as control, as described in Materials and Methods, and incubated in absence or presence of leptin $10 \mathrm{nM}$ for $48 \mathrm{~h}$. Aromatase gene expression was analyzed by qRT-PCR, normalized against RPS-7. Data represent the mean \pm s.D. value of triplicate samples in three independent experiments. Paired $t$-test was performed to examine the difference in mRNA level of aromatase, and statistical significance was considered when $P$ value was $<0.05$. * indicate significant differences from the control pcDNA3; \# indicate significant differences from the control pcDNA3 with leptin and $\wedge$ indicate significant differences from the Sam68 plasmid, according to Bonferroni's multiple comparison post hoc test. 
pathophysiology and its association with reproductive and metabolic disturbances is essential for addressing women's health and for expanding knowledge on how to treat this highly multifaceted syndrome.

Recently, a function for Sam68 in reproduction and fertility has been suggested $(13,14)$. This is a scaffold protein that could be recruited in various signal transduction pathways $(6,38)$, including leptin signaling. In the present work, we aimed to study the role of Sam68 in leptin signaling in GCs. More specifically, since Sam68 is a protein, whose structural characteristics permit multiple types of post-translational modifications, we aimed to study whether acute leptin administration affects the tyrosine phosphorylation of Sam68 in GCs. Thus, we have confirmed the Tyr-phosphorylation of Sam68 upon leptin stimulation in GCs. Moreover, this effect of leptin is dose dependent, in a similar way to that previously observed in other systems. As a result of this tyrosine phosphorylation of Sam68 in response to leptin, the RNA binding capacity of Sam68 is diminished in GCs (data not shown), being consistent with previous reported data demonstrating that tyrosine phosphorylation of Sam 68 by kinases of the Src (39) and Brk $(9,40)$ family negatively regulates its RNA binding function.

Other receptor systems have been found to positively modulate the expression of kinases substrates and other molecules recruited to the receptor signaling upon stimulation with the specific ligand (41). That is why the possible participation of Sam68 in leptin receptor signaling and the regulation of Sam68 expression by leptin in GCs from healthy donors were also investigated. In this context, we also found that leptin stimulation of GCs increased the expression of Sam68 in a similar way to that previously observed in trophoblastic cells (32). This further supports the possible role of Sam68 in the signaling of leptin in GCs. Therefore, as previously shown in many different cellular systems, leptin activates both MAPK and PI3K pathways in GCs. Now, by using both silencing gene expression strategy as well as gene overexpression, we have demonstrated that Sam68 is mediating leptin action in GCs, by the participation in the leptin-dependent activation of MAPK and PI3K signaling pathways.

Regarding the mechanism whereby Sam68 may mediate the activation of these pathways, it has previously been reported that Sam68 is associated with the SH3 and SH2 domains of proteins (39), suggesting a role of Sam68 in the MAPK pathway. Moreover, association of Tyr-phosphorylated Sam68 with the regulatory subunit of PI3K has been previously demostrated in peripheral blood mononuclear cells in response to leptin. This interaction may enhance the activation of PI3K pathway, which may support a role of Sam68 also in the activation of this pathway by leptin. Particularly, IRS- 1 is a key protein linking PI3K and MAPK signaling pathways (42). Therefore, since Sam68 seems to regulate IRS- 1 expression, as we observed in the Sam68 down-regulation (no significantly) and up-regulation experiments, the role of Sam68 stimulating PI3K and MAPK signaling pathways may be also mediated by IRS-1 in GCs. However, the mechanism whereby Sam68 may modulate IRS- 1 expression is intriguing and remains to be investigated. Thus, Sam68 plays a role in the transduction of the leptin signal from the plasma membrane to RNA metabolism via a rapid mechanism mediated by phosphorylation, and therefore, some of the effects of leptin in GCs may be mediated, at least in part, by modulation of RNA metabolism.

Leptin is a well-characterized obesity-associated factor with biological effects on survival, growth and proliferation in different biological systems (43, 44, 45). Moreover, leptin has also been shown to be a potent stimulator of aromatase expression and activity in isolated adipose stromal cells $(36,46)$ and luteinized granulosa cells $(34)$. However, some studies have shown contradictory results. In this sense, increased leptin levels in follicular fluid from women with PCOS has been found, and it may be used as a negative predictive marker in in vitro fertilization (47). Nevertheless, the increased leptin levels may be due to leptin resistance, as previously suggested (24). Thus, the investigation of the leptin action in GCs from women with or without PCOS is relevant to further understand this problem. Therefore, we also aimed to investigate the expression of aromatase by leptin stimulation and the different expression of both aromatase and Sam68 in GCs from healthy donors and women with PCOS. We found that leptin increased significantly the aromatase gene expression in GCs from healthy donors, possibly, via activation of the canonical signal transduction pathways, MAPK and PI3K, as previously shown in other cell types (34). This finding futher emphasizes the role of leptin in aromatase expression in GCs. Moreover, this study also confirms a decreased aromatase gene expression in response to leptin in GCs from women with PCOS, suggesting a significant resistance to leptin action. Since we have also found that Sam68 is downregulated in GCs from PCOS, the resistance to leptin action on aromatase expression in GCs from PCOS women may be partly mediated by the lower expression of Sam68. Moreover, basal expression of aromatase was also decreased in PCOS. This is important since hyperandrogenism is a critical factor of the pathophysiologic changes and clinical

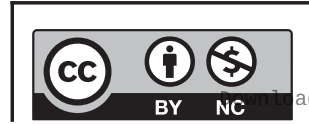

This work is licensed under a Creative Commons Attribution-NonCommercial 4.0 International License. ded from Bioscientifica.com at 04/26/2023 08:29:18AM 
features (in both lean and obese women) associated with PCOS (15). Nevertheless, it should be taken into account the limited number of women investigated in the present study. Larger studies which include more subjects should be carried out.

In summary, the current study further supports the regulation of aromatase by leptin in GCs and provides, for the first time, a novel mechanistic insight into the mechanism underlying this effect, via Sam68, as well as the possible role of this protein in leptin resistance in PCOS.

In conclusion, these results suggest the participation of Sam68 in leptin receptor signaling, mediating the leptin effect on aromatase expression in GCs, and point to a new target in leptin resistance obseved in GCs from patients with PCOS.

\section{Declaration of interest}

The authors declare that there is no conflict of interest that could be perceived as prejudicing the impartiality of the research reported.

\section{Funding}

The present work was funded by grants from the Instituto de Salud Carlos III (ISCIII), PS12/00117 and PI15/01535, funded in part by FEDER Funds, to Víctor Sánchez-Margalet.

\section{Author contribution statement}

T V-G, A P-P and E S-L performed the experiments. N P and M F-S analyzed the data. E S-L carried out the sample collection and preparation. T V-G and A P-P participated in the literature search and manuscript revision. V S-M conceived and designed the research and wrote the paper.

\section{References}

1 Chen T, Damaj BB, Herrera C, Lasko P \& Richard S. Self-association of the single-KH-domain family members Sam68, GRP33, GLD-1, and Qk1: role of the KH domain. Molecular and Cellular Biology 199717 5707-5718. (https://doi.org/10.1128/mcb.17.10.5707)

2 Lin Q, Taylor SJ \& Shalloway D. Specificity and determinants of Sam68 RNA binding. Implications for the biological function of K homology domains. Journal of Biological Chemistry 1997272 27274-27280. (https://doi.org/10.1074/jbc.272.43.27274)

3 Sánchez-Jiménez F \& Sánchez-Margalet V. Role of Sam68 in post-transcriptional gene regulation. International Journal of Molecular Sciences 201314 23402-23419. (https://doi.org/10.3390/ ijms141223402)

4 Paronetto MP, Messina V, Barchi M, Geremia R, Richard S \& Sette C. Sam68 marks the transcriptionally active stages of spermatogenesis and modulates alternative splicing in male germ cells. Nucleic Acids Research 201139 4961-4974. (https://doi.org/10.1093/nar/gkr085)

5 Lukong KE \& Richard S. Sam68, the KH domain-containing superSTAR. Biochimica et Biophysica Acta 20031653 73-86. (https:// doi.org/10.1016/j.bbcan.2003.09.001)

6 Najib S, Martín-Romero C, González-Yanes C \& Sánchez-Margalet V. Role of Sam 68 as an adaptor protein in signal transduction. Cellular and Molecular Life Sciences 200562 36-43. (https://doi.org/10.1007/ s00018-004-4309-3)

7 Taylor SJ \& Shalloway D. An RNA-binding protein associated with Src through its SH2 and SH3 domains in mitosis. Nature 1994368 867-871. (https://doi.org/10.1038/368867a0)

8 Matter N, Herrlich P \& König H. Signal-dependent regulation of splicing via phosphorylation of Sam68. Nature 2002420 691-695. (https://doi.org/10.1038/nature01153)

9 Derry JJ, Richard S, Valderrama Carvajal H, Ye X, Vasioukhin V, Cochrane AW, Chen T \& Tyner AL. Sik (BRK) phosphorylates Sam68 in the nucleus and negatively regulates its RNA binding ability. Molecular and Cellular Biology 200020 6114-6126. (https://doi. org/10.1128/mcb.20.16.6114-6126.2000)

10 Paronetto MP, Messina V, Bianchi E, Barchi M, Vogel G, Moretti C, Palombi F, Stefanini M, Geremia R, Richard S, et al. Sam68 regulates translation of target mRNAs in male germ cells, necessary for mouse spermatogenesis. Journal of Cell Biology 2009185 235-249. (https:// doi.org/10.1083/jcb.200811138)

11 Sánchez-Margalet V \& Najib S. p68 Sam is a substrate of the insulin receptor and associates with the SH2 domains of p85 PI3K. FEBS Letters 1999455 307-310. (https://doi.org/10.1016/s00145793(99)00887-x)

12 Richard S, Torabi N, Franco GV, Tremblay GA, Chen T, Vogel G, Morel M, Cléroux P, Forget-Richard A, Komarova S, et al. Ablation of the Sam68 RNA binding protein protects mice from age-related bone loss. PLoS Genetics 20051 e74. (https://doi.org/10.1371/journal. pgen.0010074)

13 Bianchi E, Barbagallo F, Valeri C, Geremia R, Salustri A, Felici M De \& Sette C. Ablation of the Sam68 gene impairs female fertility and gonadotropin-dependent follicle development. Human Molecular Genetics 201019 4886-4894. (https://doi.org/10.1093/hmg/ddq422)

14 Sette C, Messina V \& Paronetto MP. Sam68: a new STAR in the male fertility firmament. Journal of Andrology 201031 66-74. (https://doi. org/10.2164/jandrol.109.008136)

15 Azziz R, Carmina E, Dewailly D, Diamanti-Kandarakis E, EscobarMorreale HF, Futterweit W, Janssen OE, Legro RS, Norman RJ, Taylor AE, et al. The androgen excess and PCOS Society criteria for the polycystic ovary syndrome: the complete task force report. Fertility and Sterility 200991 456-488. (https://doi.org/10.1016/j. fertnstert.2008.06.035)

16 Dasgupta S \& Reddy BM. Present status of understanding on the genetic etiology of polycystic ovary syndrome. Journal of Postgraduate Medicine 200854 115-125. (https://doi.org/10.4103/0022-3859.40778)

17 Hart R \& Doherty DA. The potential implications of a PCOS diagnosis on a woman's long-term health using data linkage. Journal of Clinical Endocrinology and Metabolism 2015100 911-919. (https:// doi.org/10.1210/jc.2014-3886)

18 Codner E, Iñíguez G, López P, Mujica V, Eyzaguirre FC, Asenjo S, Torrealba I \& Cassorla F. Metformin for the treatment of hyperandrogenism in adolescents with type 1 diabetes mellitus. Hormone Research in Paediatrics 201380 343-349. (https://doi. org/10.1159/000355513)

19 Naderpoor N, Shorakae S, Courten B de, Misso ML, Moran LJ \& Teede HJ. Metformin and lifestyle modification in polycystic ovary syndrome: systematic review and meta-analysis. Human Reproduction Update 201521 560-574. (https://doi.org/10.1093/humupd/dmv025)

20 Rich-Edwards JW, Goldman MB, Willett WC, Hunter DJ, Stampfer MJ, Colditz GA \& Manson JE. Adolescent body mass index and infertility caused by ovulatory disorder. American Journal of Obstetrics and Gynecology 1994171 171-177. (https://doi. org/10.1016/0002-9378(94)90465-0)

21 Blüher S \& Mantzoros CS. Leptin in reproduction. Current Opinion in Endocrinology, Diabetes, and Obesity 200714 458-464. (https://doi org/10.1097/MED.0b013e3282f1cfdc)

22 Baig M, Rehman R, Tariq S \& Fatima SS. Serum leptin levels in polycystic ovary syndrome and its relationship with metabolic

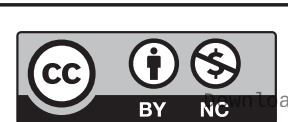

This work is licensed under a Creative Commons Attribution-NonCommercial 4.0 International License. ded from Bioscientifica.com at 04/26/2023 08:29:18AM 
and hormonal profile in Pakistani females. International Journal of Endocrinology 20142014 132908. (https://doi. org/10.1155/2014/132908)

23 Sepilian VP, Crochet JR \& Nagamani M. Serum soluble leptin receptor levels and free leptin index in women with polycystic ovary syndrome: relationship to insulin resistance and androgens. Fertility and Sterility 200685 1441-1447. (https://doi.org/10.1016/j fertnstert.2005.10.038)

24 Li MG, Ding GL, Chen XJ, Lu XP, Dong LJ, Dong MY, Yang XF, Lu XE \& Huang HF. Association of serum and follicular fluid leptin concentrations with granulosa cell phosphorylated signal transducer and activator of transcription 3 expression in fertile patients with polycystic ovarian syndrome. Journal of Clinical Endocrinology and Metabolism 200792 4771-4776. (https://doi.org/10.1210/jc.20070978)

25 Daan NMP, Louwers YV, Koster MPH, Eijkemans MJC, Rijke YB de, Lentjes EWG, Fauser BCJM \& Laven JSE. Cardiovascular and metabolic profiles amongst different polycystic ovary syndrome phenotypes: who is really at risk? Fertility and Sterility 20141021444. e3-1451.e3. (https://doi.org/10.1016/j.fertnstert.2014.08.001)

26 Rotterdam ESHRE/ASRM-Sponsored PCOS Consensus Workshop Group. Revised 2003 consensus on diagnostic criteria and long-term health risks related to polycystic ovary syndrome. Fertility and Sterility 200481 19-25. (https://doi.org/10.1016/j.fertnstert.2003.10.004)

27 Ferrero H, Díaz-Gimeno P, Sebastián-León P, Faus A, Gómez R \& Pellicer A. Dysregulated genes and their functional pathways in luteinized granulosa cells from PCOS patients after cabergoline treatment. Reproduction 2018155 373-381. (https://doi.org/10.1530/ REP-18-0027)

28 Pérez-Pérez A, Sánchez-Jiménez F, Vilariño-García T, la Cruz L de, Virizuela JA \& Sánchez-Margalet V. Sam68 mediates the activation of insulin and leptin signalling in breast cancer cells. PLOS ONE 201611 e0158218. (https://doi.org/10.1371/journal.pone.0158218)

29 Smith PK, Krohn RI, Hermanson GT, Mallia AK, Gartner FH, Provenzano MD, Fujimoto EK, Goeke NM, Olson BJ \& Klenk DC. Measurement of protein using bicinchoninic acid. Analytical Biochemistry 1985150 76-85. (https://doi.org/10.1016/00032697(85)90442-7)

30 Sanchez-Margalet V \& Martin-Romero C. Human leptin signaling in human peripheral blood mononuclear cells: activation of the JAK-STAT pathway. Cellular Immunology 2001211 30-36. (https://doi. org/10.1006/cimm.2001.1815)

31 Sánchez-Margalet V, González-Yanes C, Najib S, Fernández-Santos JM \& Martín-Lacave I. The expression of Sam68, a protein involved in insulin signal transduction, is enhanced by insulin stimulation. Cellular and Molecular Life Sciences 200360 751-758. (https://doi. org/10.1007/s00018-003-2342-2)

32 Sánchez-Jiménez F, Pérez-Pérez A, González-Yanes C, Najib S, Varone CL \& Sánchez-Margalet V. Leptin receptor activation increases Sam68 tyrosine phosphorylation and expression in human trophoblastic cells. Molecular and Cellular Endocrinology 2011332 221-227. (https://doi.org/10.1016/j.mce.2010.10.014)

33 Catalano S, Marsico S, Giordano C, Mauro L, Rizza P, Panno ML \& Andò S. Leptin enhances, via AP-1, expression of aromatase in the MCF-7 cell line. Journal of Biological Chemistry 2003278 28668-28676. (https://doi.org/10.1074/jbc.M301695200)

34 Kitawaki J, Kusuki I, Koshiba H, Tsukamoto K \& Honjo H. Leptin directly stimulates aromatase activity in human luteinized granulosa cells. Molecular Human Reproduction 19995 708-713. (https://doi. org/10.1093/molehr/5.8.708)

35 Magoffin DA, Weitsman SR, Aagarwal SK \& Jakimiuk AJ. Leptin regulation of aromatase activity in adipose stromal cells from regularly cycling women. Ginekologia Polska 199970 1-7.

36 Masarwi M, Shamir R, Phillip M \& Gat-Yablonski G. Leptin stimulates aromatase in the growth plate: limiting catch-up growth efficiency. Journal of Endocrinology 2018237 229-242. (https://doi. org/10.1530/JOE-18-0028)

37 Norman RJ, Dewailly D, Legro RS \& Hickey TE. Polycystic ovary syndrome. Lancet 2007370 685-697. (https://doi.org/10.1016/ S0140-6736(07)61345-2)

38 Maroni P, Citterio L, Piccoletti R \& Bendinelli P. Sam68 and ERKs regulate leptin-induced expression of OB-Rb mRNA in C2C12 myotubes. Molecular and Cellular Endocrinology 2009309 26-31. (https://doi.org/10.1016/J.MCE.2009.05.021)

39 Najib S \& Sánchez-Margalet V. Sam68 associates with the SH3 domains of Grb2 recruiting GAP to the Grb2-SOS complex in insulin receptor signaling. Journal of Cellular Biochemistry 200286 99-106. (https://doi.org/10.1002/jcb.10198)

40 Haegebarth A, Heap D, Bie W, Derry JJ, Richard S \& Tyner AL. The nuclear tyrosine kinase BRK/Sik phosphorylates and inhibits the RNA-binding activities of the Sam68-like mammalian proteins SLM-1 and SLM-2. Journal of Biological Chemistry $200427954398-54404$. (https://doi.org/10.1074/jbc.M409579200)

41 Johnston AM, Pirola L \& Obberghen E Van. Molecular mechanisms of insulin receptor substrate protein-mediated modulation of insulin signalling. FEBS Letters 2003546 32-36. (https://doi.org/10.1016/ S0014-5793(03)00438-1)

42 Szanto I \& Kahn CR. Selective interaction between leptin and insulin signaling pathways in a hepatic cell line. PNAS 200097 2355-2360. (https://doi.org/10.1073/pnas.050580497)

43 Pérez-Pérez A, Toro AR, Vilarino-Garcia T, Guadix P, Maymó JL, Dueñas JL, Varone CL \& Sánchez-Margalet V. Leptin reduces apoptosis triggered by high temperature in human placental villous explants: the role of the p53 pathway. Placenta 201642 106-113. (https://doi.org/10.1016/j.placenta.2016.03.009)

44 Pérez-Pérez A, Maymó J, Dueñas JL, Goberna R, Calvo JC, Varone C \& Sánchez-Margalet V. Leptin prevents apoptosis of trophoblastic cells by activation of MAPK pathway. Archives of Biochemistry and Biophysics 2008477 390-395. (https://doi.org/10.1016/J. ABB.2008.06.015)

45 Pérez-Pérez A, Maymó J, Gambino Y, Dueñas JL, Goberna R, Varone C \& Sánchez-Margalet V. Leptin stimulates protein synthesisactivating translation machinery in human trophoblastic cells. Biology of Reproduction 200981 826-832. (https://doi.org/10.1095/ biolreprod.109.076513)

46 Dieudonné MN, Sammari A, Dos E, Leneveu MC, Giudicelli Y \& Pecquery R. Sex steroids and leptin regulate 11beta-hydroxysteroid dehydrogenase I and P450 aromatase expressions in human preadipocytes: sex specificities. Journal of Steroid Biochemistry and Molecular Biology 200699 189-196. (https://doi.org/10.1016/j. jsbmb.2006.01.007)

47 Mantzoros CS, Cramer DW, Liberman RF \& Barbieri RL. Predictive value of serum and follicular fluid leptin concentrations during assisted reproductive cycles in normal women and in women with the polycystic ovarian syndrome. Human Reproduction 200015 539-544. (https://doi.org/10.1093/humrep/15.3.539)
Received in final form 19 April 2020

Accepted 6 May 2020

Accepted Manuscript published online 6 May 2020 https://ec.bioscientifica.com https://doi.org/10.1530/EC-20-0062 (c) 2020 The authors Published by Bioscientifica Ltd

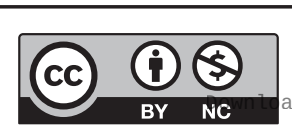

This work is licensed under a Creative Commons Attribution-NonCommercial 4.0 International License. ded from Bioscientifica.com at 04/26/2023 08:29:18AM 